\title{
Chemiluminescence immunoassay
}

\author{
Lixia Zhao, Li Sun, Xiaogang Chu
}

\begin{abstract}
Chemiluminescence immunoassay (CLIA) offers several potential advantages and has applications in clinical chemistry, bioanalysis and environmental analysis. This review covers recent developments and applications of CLIA in immunorecognition, CL markers and related techniques, and solid-phase materials. We describe automation, integration and miniaturization of CLIA. We evaluate different CLIA systems and give some pointers as to the likely directions of future developments.
\end{abstract}

(c) 2009 Elsevier Ltd. All rights reserved.

Keywords: Bioanalysis; Chemiluminescence immunoassay; Chemiluminescence marker; Clinical chemistry; Environmental analysis; Immunorecognition; Label; Pharmaceutical analysis; Solid-phase material; Toxicological analysis

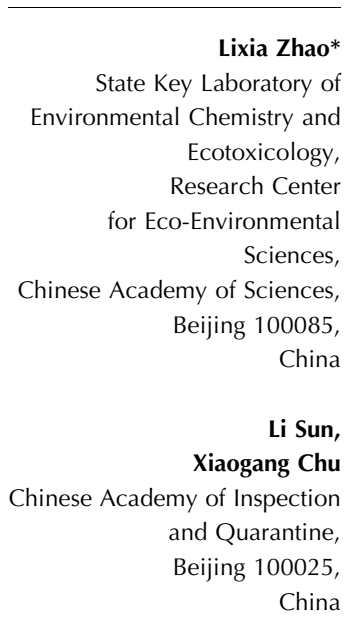

*Corresponding author.

Tel./Fax: +86 1062841953

E-mail: zlx@rcees.ac.cn

\section{Introduction}

Immunoassay (IA) as an analytical technique is widely applied in pharmaceutical analysis, toxicological analysis, bioanalysis, clinical chemistry, and environmental analysis, due to its high sensitivity, high selectivity, rapid detection and possible analysis of difficult matrices without extensive pre-treatment.

Radioimmunoassay (RIA) has been developed since Yalow and Berson [1] introduced it in 1959 by using ${ }^{125} \mathrm{I}$ as a label. Although RIA methods are reliable and accurate, they suffer from the problems associated with radioisotopes, which restrict their use to specialized laboratories. They also suffer from the drawback of the short half-life using ${ }^{125} \mathrm{I}$ as a label $[2,3]$.

Enzyme-linked immunosorbent assays (ELISAs) are among the most extensively used types of IA and are safer and easier than the RIA. ELISA could be based on colorimetric, fluorescence or chemiluminescence (CL) detection. However, the sensitivity of conventional colorimetric detection is relatively low [4]. IA has been applied to develop assays with very highsensitivity detection $[5,6]$, which strongly depends on the affinity of specific antibodies (Abs) and on the sensitivity of the detection method.

Among assay methods, CL detection represents a versatile, ultrasensitive tool with a wide range of applications in biotechnology. It also gives a sensitive, rapid alternative to radioactivity as a detection principle in IA for the determination of molecules (e.g., proteins, hormones, drugs, nucleic acids and environmental pollutants). CL is now commonly used for IA in the form of a CL label or as a CLdetection reaction for an enzyme or a nanoparticle (NP) label. In recent years, CLIA has become very popular in clinical chemistry and environmental analysis, due to its high sensitivity, wide dynamic range and complete automation. With the development and application of recombinant $\mathrm{Ab}(\mathrm{rAb})$ technology, markers and related techniques, solid-phase materials and improvements in automation, integration and miniaturization, CLIA has acquired an entirely new appearance.

\section{Immunorecognition}

Polyclonal and monoclonal Abs (pAbs and mAbs) have dominated IA in the past and will continue to do so in the future [7]. Conventionally, Abs are obtained from hyper-immunized animals or hybridoma cells. To date, many animals (e.g., rabbits, sheep, chickens and cattle) have been used to produce pAbs, which are relatively inexpensive for large quantities, but which cross-react with structurally similar compounds and the co-contaminants presented in analytes exhibit matrix effects on the pAb-based assay.

While mAbs are usually produced from mice [8], they possess specific binding characteristics and an assay based on mAbs is more sensitive than a pAb-based assay. The main drawback of producing $\mathrm{mAbs}$ is that they are expensive, and it is technically demanding to generate and to maintain a hybridoma cell line [9]. The binding characteristics of the $\mathrm{mAb}$ are predetermined by the immune response of the 
Table 1. Selected examples of recombinant antibodies for immunoassay

\begin{tabular}{|lll|}
\hline \multicolumn{1}{|c}{ Analytes } & Antibody fragments & Ref. \\
\hline Atrazine & Fabs from hybridoma & {$[12]$} \\
Chlorpyrifo-ethyl & scFv from hybridoma & {$[13]$} \\
PCBs & Fabs from hybridoma & {$[14]$} \\
Cell-surface proteomics & Human recombinant scFv & {$[15]$} \\
Dioxin(2,3,7,8-TCDD) & Fab from hybridoma & {$[16]$} \\
fPSA, fhK2, thK2 & Recombinant Fab & {$[17]$} \\
$\beta 2$-agonist clenbuterol & scFv from hybridoma & {$[18]$} \\
Fumonisin B1 & scFv from hybridoma & {$[19]$} \\
Methamidophos & Mouse scFv & {$[20]$} \\
Domoic acid & Sheep scFv & {$[21]$} \\
\hline
\end{tabular}

fPSA, Free prostate-specific antigen; fhK2, Free human kallikrein 2; thK2, Total human kallikrein 2.

animals and are difficult to modify at the protein level [10]. However, the development of molecular methods for expression of $\mathrm{Ab}$ fragments and techniques for producing and screening combinatorial libraries have opened up a wide range of opportunities for selecting and engineering rAbs [11]. Table 1 shows that rAbs can be now produced from various animals without the need for a myeloma cell line as fusion partner. Ab genes from these animals can be amplified by polymerase chain reaction (PCR) and expressed in different expression systems in various formats [e.g., fragment, antigenbinding (Fab), fragment, variable domain (Fv), singlechain $\mathrm{Fv}(\mathrm{scFv})$ and the heavy-chain variable fragment (VHH) of single-domain heavy-chain Abs (HCAbs) from camelids (as shown in Fig. 1)]. These Ab fragments have three major advantages:

(1) they are smaller in size and therefore easier to manipulate genetically and express in bacterial systems;

(2) they can be expressed and anchored on bacteriophage surfaces as fusion proteins; and,

(3) when displayed, they remain functional for the purpose of affinity selection.

As a result, rAbs offer advantages over traditional mAbs or pAbs in terms of ease of production, increased repertoire for selection, and versatility. The production and the selection of $\mathrm{Ab}$ fragments from large phage

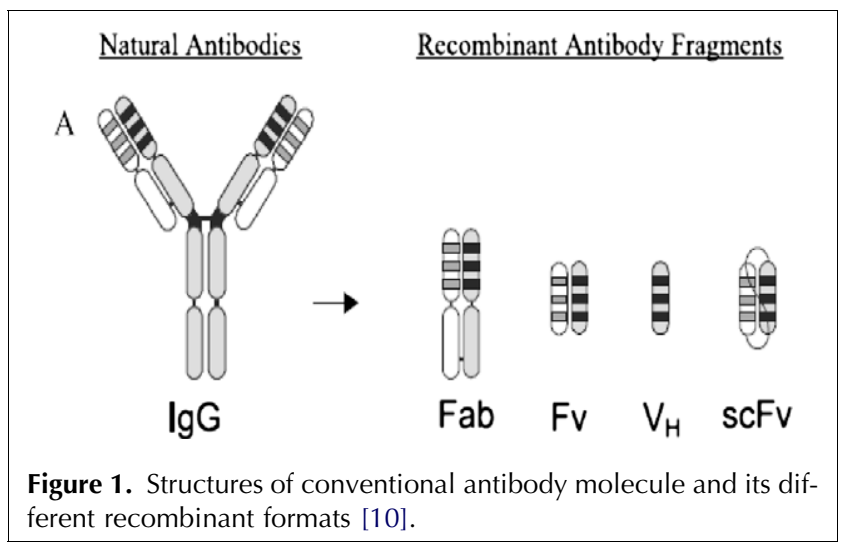

libraries has become a common method for generating specific Abs. The technique is particularly valuable when Abs have to be produced against small, nonimmunogenic molecules (haptens) or highly toxic substances. In addition, haptens are usually coupled to protein carriers, bearing the risk that the free hapten is not detectable.

Pan et al. [18] using phage-display technology to produce $\mathrm{scFv}$ directed against $\beta_{2}$-agonist clenbuterol (CBL). Phages displaying scFv were enriched by panning with CBL-ovalbumin (CBL-OVA) conjugate. The scFv showed improved sensitivity (with $\mathrm{IC}_{50}$ of $0.78 \pm$ $0.005 \mathrm{ng} / \mathrm{mL}(\mathrm{n}=4))$ compared with the parent $\mathrm{mAb}$ (with $\mathrm{IC}_{50}$ of $1.34 \pm 0.006 \mathrm{ng} / \mathrm{mL}(\mathrm{n}=4)$ ) in competitive indirect ELISA (CI-ELISA).

Lauer et al. [19] produced scFv against highly-toxic mycotoxin fumonisin $\mathrm{B}_{1}$, and the hapten was coupled via a linker to biotin. Using this conjugation and a naive scFv library, it was possible to circumvent both the need for immunization and the risk of a disguised hapten.

Shaw et al. [21] described the development of rAbs $(\mathrm{scFv})$ against the common shellfish toxin, domoic acid (DA), utilizing the sheep immunoglobulin system as an effective method for generating high-affinity anti-hapten $\mathrm{rAb}$ fragments.

In addition, plants and crop species have the potential to enable extremely cost effective and efficient production of Abs [22].

For the assay of real samples, denaturation of Abs by the organic co-solvent needed to dissolve hydrophobic analytes in aqueous solution is a serious problem, so the design and the synthesis of biomimetic Abs that can bind specifically a target molecule has long been a goal. In the past few years, molecularly imprinted polymers (MIPs) have increasingly attracted attention as substitutes for Abs in immunoanalysis (in, e.g., binding assays, biosensors and solid-phase immunoextraction [23]) due to their selectivity, ease of preparation, low price, and better physical and chemical stability.

As to IA, Table 2 lists reports using MIPs instead of Abs for IA. Although the first report in which MIPs 
Table 2. Reports using molecularly imprinted polymer (MIP) instead of antibody in chemiluminescence immunoassay

\begin{tabular}{|c|c|c|c|}
\hline Analytes & MIP polymer preparation & Immunoassay format & Ref. \\
\hline Atrazine & $\mathrm{MAA}+\mathrm{EGDMA}+\mathrm{AMVN}$ & Competitive & {$[25]$} \\
\hline Epinephrine & $\mathrm{APBA}+(\mathrm{NH} 4)_{2} \mathrm{~S}_{2} \mathrm{O}_{8}$ & Competitive & {$[26]$} \\
\hline Fluorescein and 2,4-D & $4-V P+T R I M+D P A P$ & Competitive & {$[27]$} \\
\hline $2,4-\mathrm{D}$ & $4-V P+T R I M+A I B N$ & Competitive & {$[28,2]$} \\
\hline 2,4-D & $4-V P+E G D M A$ & & [29] \\
\hline Glutamic acid & Silane-treated alumina membrane modified aldehyde group (nanowire) & & {$[30]$} \\
\hline
\end{tabular}

MAA, Methacrylic acid; EGDMA, Ethylene glycol dimethacrylate; AMVN, 2,2'-azobid(2,4-dimethylvaleronitrile); APBA, 3-aminophenylboronic acid; 4-VP, 4-vinylpyridine; TRIM, Trimethylolpropane trimethacrylate; DPAP, 2,2-dimethoxy-2-phenylacetophenone; AIBN, 2,2'-azobisisobutyronitrile.

substituted for Abs dates back about 15 years [24], there is still no MIP-based assay available commercially, partly because the compatibility of MIPs with many modern IA formats remains to be demonstrated [28].

\section{Labels}

Reagents required for reactions that produce CL may be coupled to Abs or antigens (Ags) and used as labels for IA. Since the first report on CL labels in 1976 [31], considerable efforts have been devoted to developing practical CL-labeling systems because of their low limits of detection (LODs) [32]. Luminol, isoluminol and its derivatives, acridinium ester, horseradish peroxidase (HRP) and alkaline phosphatase (ALP) have frequently been employed as CL labels in IA for development and application of CLIA methods. Because the CL-detection methods have very low LODs, new CL labels and related substrates, new label technologies have been studied and obtained staggering results. In this section, we categorize CL labels developed in recent years into two different types and review them. One comprises labels that are consumed in the analytical reaction, the other labels that are not consumed in producing light.

\subsection{Labels that are consumed}

This category involves labels that are consumed in the CL analytical reaction (e.g., luminol derivatives, acridinium esters and NPs).

Luminol is the best known and one of the most efficient CL reagents. It is coupled to ligands via reactions involving the amino group. However, the resulting conjugates have lower CL efficiencies than the parent compounds. Labels derived from isoluminol have been more successful.

Aromatic acridinium esters with CL were produced when oxidized by hydrogen peroxide and Abs or Agderived conjugates can be detected at high sensitivity. The performance of this label is similar to that of isoluminol, so considerable effort has been devoted to evaluating the effect of structure on the CL efficiency of isoluminol or acridinium-ester derivatives suitable for coupling as well as to determining the oxidizing reagents that provide the lowest LOD.

Chen et al. [33] synthesized a new biacridine compound, 10,10-dimethyl-3, 3-disulfo-9, 9-biacridine (DMDSBA) as a CL label and established a sandwich CLIA method for the determination of carcino-embryonic Ag (CEA) in human serum, the calibration range was $1.0-100 \mathrm{ng} / \mathrm{mL}$ and the minimal detectable concentration of CEA was $0.53 \mathrm{ng} / \mathrm{mL}$. After BMDSBA attached to the anti-CEA $A b$, there were no obvious changes in the immunoreactivity of the labeled anti-CEA $\mathrm{Ab}$ and the quantum efficiency of DMDSBA. The average labeling ratio was 1.25 .

Scorilas et al. [34] synthesized two novel biotinylated acridinium derivatives, 9-(2-biotinyl-oxyethyl)-carboxylate-10-methyl-acridinium triflate (BOCMAT) and 9-(2biotinyl-amidoethyl)-carboxylate-10-methyl-acridinium triflate (BACMAT), and described their luminescent properties and IA applications. The CL efficiency of the novel reagents was high in polar aprotic solvents and attained LODs down to $7.28 \times 10^{-8} \mathrm{~mol} / \mathrm{L}$. The novel compounds were applied to determination of biotinylated mouse IgG. However, the sensitivity, the stability and the linear range of these methods using these CL regents as labels were unsatisfactory [35].

Recently, the method using NPs, especially metal NPs, as biological labels has attracted considerable interest. As biological labels, NPs present many advantages [36-38]:

- first, a variety of nanostructures with unique properties at nanoscale dimensions are easily prepared, so that has attracted widespread interest in their use in biotechnological systems; and,

- second, NPs are more suitable for conjugation with biological systems because they have a good biocompatibility and are similar in size range to many macrobiomolecules.

In recent years, there have been many CLIAs using different NPs as labels for detection analytes. Table 3 [39-47] shows various NPs as CL labels and the corresponding CL detection system in the IA. When using the 
$\mathrm{Au}$ NP as the CL label, the systems have usually been based on the sensitive $\mathrm{Au}^{3+}$-catalyzed luminol CL reaction $[39,41,43,47] . \mathrm{Au}^{3+}$, which is the dissolution product of the Au NPs bound to the Ab or Ag, served as the analyte in the CL reaction for the indirect measurement of $\mathrm{Ab}$ or $\mathrm{Ag}$.

In an IA model, Li et al. [39] explored Au NPs as CL labels using human $\operatorname{IgG}$, goat-anti-human $\operatorname{IgG}$ and rabbit-anti-goat IgG-functionalized Au NPs. Human IgG was first immobilized to the solid phase as the Ag. Afterwards, the bound Ag was used to capture goatanti-human IgG $\mathrm{Ab}$ that would then capture the second rabbit-anti-goat $\mathrm{Ab}$ labeled with $\mathrm{Au}$ NPs. The $\mathrm{Au}$ NPs adsorbed in the solid phase were dissolved to $\mathrm{AuCl}^{4-}$, which had a strong catalytic effect on the luminol- $\mathrm{H}_{2} \mathrm{O}_{2}$ $\mathrm{CL}$ reaction. The CL signals of the $\mathrm{AuCl}^{4-}-$ luminol- $\mathrm{H}_{2} \mathrm{O}_{2}$ $\mathrm{CL}$ reaction were measured and used to detect the goat-anti-human IgG in the immunoreaction. The CL intensity was proportional to the logarithm of the concentration of goat-anti-human IgG in the range $0.005-10 \mu \mathrm{g} / \mathrm{mL}$ and the LOD $(3 \sigma)$ was $1.5 \mathrm{ng} / \mathrm{mL}$. From the analytical chemistry point of view, this protocol would be quite promising for numerous applications in IA and DNA hybridization [43].

Two years later, Li et al. [47] developed a CLIA method for DNA hybridization based on the same sandwich-type model and Au label. Au NPs modified with alkylthiol-capped oligonucleotide strands were used as probes to monitor the presence of the specific target DNA. $\mathrm{AuCl}^{4-}$, which was the dissolution product of the $\mathrm{Au}$ NPs anchored on the DNA hybrids, served as an analyte in the $\mathrm{H}_{2} \mathrm{O}_{2}$-luminol-AuCl ${ }^{4-}$ CL reaction for indirect measurement of the target DNA. The combination of the remarkable sensitivity of CL analysis with the large number of $\mathrm{AuCl}^{4-}$ ions released from each DNA hybrid allowed an LOD as low as $0.1 \mathrm{pM}$ of the target DNA.

Han et al. [41] reported a CLIA based on the Auion-enhanced luminol CL reaction for detection of ApxIV $\mathrm{Ab}$ from Actinobacillus pleuropneumoniae (APP). The purified recombinant ApxIV protein was adsorbed passively on the surface of polystyrene wells. The $\mathrm{Ab}$ in the serum samples was captured by the recombinant ApxIV protein and then sandwiched by Au NP-rabbit anti-pig IgG conjugate. Next, the unbound Au NP-rabbit anti-pig IgG conjugate was removed. A large number of $\mathrm{AuCl}^{4-}$ ions from $\mathrm{Au}$ NPs anchored on the surface of polystyrene wells were released in an oxidative $\mathrm{HCl}-\mathrm{NaCl}-\mathrm{Br}_{2}$ solution, and then quantitatively determined by a simple, sensitive $\mathrm{AuCl}^{4-}$-enhanced luminol CL reaction. Under optimal conditions, a good correlation between relative CL photon counting and the dilution coefficient of serum was obtained in the dilution range 1:160-1:40 000 .

CLIA has remarkable advantages in terms of reliability and practical use compared with indirect hemagglutination assay (IHA) and ELISA. Wang et al. [45] synthesized specially shaped, irregular Au NPs and found their catalytic efficiency on luminol CL to be 100-fold greater than that of spherical Au NPs. Using irregular $\mathrm{Au}$ NP-functionalized DNA oligomers and irregular $\mathrm{Au}$ NP-modified anti-IgG as in situ CL probes, they established sandwich-type analytical methods for rapid, simple, selective and sensitive sequence-specific DNA detection and for human plasma IgG IA, respectively. The CL metallimmunoassay was also developed using a silver-NP label for the ultrasensitive detection of DNA hybridization [40] or using silver precipitation on colloidal $\mathrm{Au}$ tags for the sensitive determination of hIgG [44]. Silver NPs were dissolved to $\mathrm{Ag}^{+}$in $\mathrm{HNO}_{3}$ solution and sensitively determined by a combined CL reaction system $\left(\mathrm{Ag}^{+}-\mathrm{Mn}^{2+}-\mathrm{K}_{2} \mathrm{~S}_{2} \mathrm{O}_{8}-\mathrm{H}_{3} \mathrm{PO}_{4}\right.$-luminol). The combination of the remarkable sensitivity of the CL method with the large number of $\mathrm{Ag}^{+}$ions released from each hybrid allowed detection of specific-sequence DNA targets at levels of $5 \mathrm{fM}$ and human IgG with an LOD of $0.005 \mathrm{ng} / \mathrm{mL}$.

Highly luminescent quantum dots (QDs) have also received tremendous attention. With size-tunable, narrow emission spectra and broad excitation spectra, they have been widely used as biological luminescent labels $[48,49]$.

Jie et al. [46] described an electrochemiluminescence (ECL) immunosensor based on CdSe QDs for the detection of human prealbumin (PAB). The principle of ECL

Table 3. Some reports using nanoparticles (NPs) as labels in chemiluminescence immunoassay

\begin{tabular}{|c|c|c|c|c|c|}
\hline Analyte & NPs & Assay format & Detection system & Limit of detection (LOD) & Ref. \\
\hline hlgG & $\mathrm{Au}$ & Sandwich & $\mathrm{AuCl}^{4-}-$ Luminol- $\mathrm{H}_{2} \mathrm{O}_{2}$ & $\begin{array}{l}1.5 \mathrm{ng} / \mathrm{mL} \\
3.1 \times 10^{-12} \mathrm{M}\end{array}$ & {$[39,43]$} \\
\hline DNA & Silver & Sandwich & $\mathrm{Ag}^{+}-\mathrm{Mn}^{2+}-\mathrm{K}_{2} \mathrm{~S}_{2} \mathrm{O}_{8}-\mathrm{H}_{3} \mathrm{PO}_{4}-$ Lumino & $5 \mathrm{fM}$ & {$[40]$} \\
\hline Antibody against ApxIV & $\mathrm{Au}$ & Indirect measurement & $\mathrm{AuCl}^{4-}-\mathrm{HCl}-\mathrm{NaCl}-\mathrm{Br}_{2}-$ Luminol & & [41] \\
\hline $\mathrm{mlgG}$ & $\mathrm{Au}-\mathrm{Ag}$ & Indirect sandwich & CCD & $0.1 \mu \mathrm{g} / \mathrm{mL}$ & [42] \\
\hline hlgG & $\mathrm{Au}-\mathrm{Ag}$ & Sandwich & $\mathrm{Ag}^{+}-\mathrm{K}_{2} \mathrm{~S}_{2} \mathrm{O}_{8}-\mathrm{Mn}^{2+}-\mathrm{H}_{3} \mathrm{PO}_{4}-$-Lumino & $0.005 \mathrm{ng} / \mathrm{mL}$ & [44] \\
\hline DNA, hlgG & Irregular Au & Sandwich & $\mathrm{Au}-$ Luminol- $\mathrm{H}_{2} \mathrm{O}_{2}$ & $\begin{array}{l}13 \mathrm{pmol} / \mathrm{L} \text { (DNA) } \\
17 \mathrm{pmol} / \mathrm{L}(\mathrm{IgG})\end{array}$ & {$[45]$} \\
\hline Human prealbumin (PAB) & CdSe & & $\mathrm{ECL}\left(\mathrm{CdSe}-\mathrm{K}_{2} \mathrm{~S}_{2} \mathrm{O}_{8}\right)$ & $1.0 \times 10^{-11} \mathrm{~g} / \mathrm{mL}$ & {$[46]$} \\
\hline DNA & $\mathrm{Au}$ & Sandwich & $\mathrm{AuCl}^{4-}-$ Luminol- $\mathrm{H}_{2} \mathrm{O}_{2}$ & $0.1 \mathrm{pM}$ & [47] \\
\hline
\end{tabular}




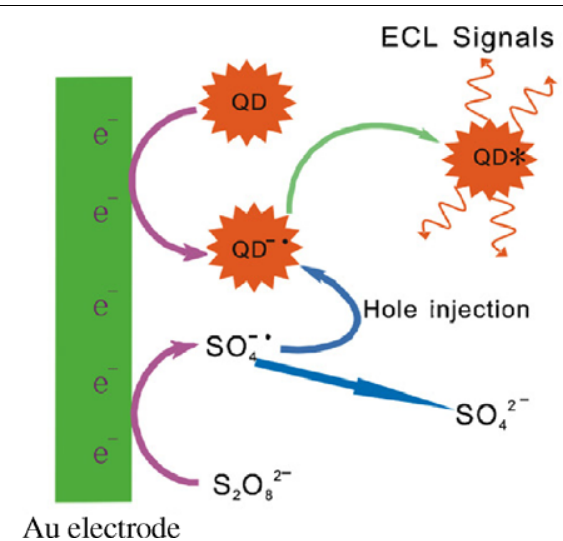

Figure 2. Electrochemiluminescence mechanisms of nanoparticles [46].

detection (shown in Fig. 2) was that the immunocomplex inhibited the ECL reaction between CdSe QDs and $\mathrm{K}_{2} \mathrm{~S}_{2} \mathrm{O}_{8}$, which reduced ECL intensity. PAB concentration was determined in the range $5.0 \times 10^{-10}-1.0 \times$ $10^{-6} \mathrm{~g} / \mathrm{mL}$, and the LOD was $1.0 \times 10^{-11} \mathrm{~g} / \mathrm{mL}$.

\subsection{Labels that are not consumed}

This category of CL label is not consumed but catalyzes light production. It mainly includes enzyme labels \{e.g., alkaline phosphatase (AP) [50], $\beta$-D-galactosidase and horseradish peroxidase (HRP) [51]\}. These labels require suitable substrates. In order to obtain a low LOD, highly sensitive CL detection systems have recently developed for detecting these labels in CLIA. HRP is a particularly popular label, and rapid, sensitive methods for detection of common HRPs are feasible with several CL systems.

HRP has a cationic isoenzyme $c$ (HRP-C) of the peroxidase purified from horseradish roots. It catalyzes the luminescent reaction between a hydrogen acceptor (oxidant) (e.g., hydrogen peroxide or carbamide peroxide) and a hydrogen donor, including CL substrates (e.g., luminol). When oxidized, luminol emits light, which rapidly decreases after few minutes. But the sensitivity and CL platform is limited in the application of CLIA, so there have been many studies of enhancers and stable additives to increase the reaction efficiency so as to provide more intense, prolonged and stable light emissions in CLIA. The most popular enhancer of the HRP-catalyzed CL oxidation of luminol is 4-iodophenol (PIP) [52].

For the lumiol- $\mathrm{H}_{2} \mathrm{O}_{2}$-HRP system, Luo et al. [53] described the synergistic action of para-phenylphenol and sodium tetraphenylborate (NaTPB), which can improve sensitivity. In addition, a variety of substituted phenols [e.g., firefly luciferin, 6-hydroxybenzothiazole derivatives and substituted arylboronic acid derivatives (e.g., 4iodophenylboronic acid or more complicated ones)] have been applied as luminol signal enhancers [54].
Dotsikas et al. [54,55] developed and compared several different luminol-signal enhancers [i.e. 4-methoxylphenol (4-MEP), 4-(1-imidazolyl)phenol (4-IMP), 4-iodophenol (4-IOP), 4-hydroxybiphenyl (4-BIP), and 4-(1H-pyrrol-1-yl)phenol (4-PYP)] using the CL heterogeneous enzyme IA for fentanyl as a model assay. The results showed that the effect of each phenol enhancer on CL intensity, LOD and CL kinetics profile was very different for the different substituents. This was probably because the electronic properties (i.e. extent of resonance effect) of the substituents played a critical role on radical stabilization and therefore on CL-intensity enhancement. Also, electron-donating groups had a similar effect (reduction) on $\mathrm{O}-\mathrm{H}$ bond-dissociation energy, and therefore stabilized phenoxyl radicals [56,57]. The phenoxyl radical was assumed to affect the luminol CL intensity.

On the other hand, the anionic peroxidase isolated from different plants \{e.g., leaves of African oil palm tree (AOPTP) [58], orshells of soybeans (SbP) $[59,60]\}$ were also studied. The results showed that anionic peroxidase could efficiently catalyze the luminol- $\mathrm{H}_{2} \mathrm{O}_{2}$ CL in the absence of any enhancer. Furthermore, the feature of this peroxidase is the production of a long-term signal of CL through luminol oxidation. Therefore, this fact permits us to look forward to the construction of new highly sensitive CL immuno-enzymatic kits without using enhancers and stabilizing additives.

\section{Solid-phase materials}

Commonly used solid-phase are 96-well microtitration plates prepared with polystyrene. For the purposes of IA, the microplates are pre-coated with capturing protein [61-63] like $\mathrm{Ab}$ to allow analyte immobilization. However, direct adsorption of Abs on the plastic surface may adversely influence the test performance such as reproducibility, sensitivity, cost etc. Zhao et al. [64] developed two different solid phases based on the avidinbiotin system and the fluorescein-iso-thiocyanate (FITC)anti-FITC system for the determination of albumin in urine. Avidin or anti-FITC Ab was coated in the microplates to provide a universal solid phase which improved the variability and sensitivity. For the two solid phases, the linear range and the LOD of albumin were $0.15 \sim 15 \mu \mathrm{g} / \mathrm{mL}$ and $0.089 \mu \mathrm{g} / \mathrm{mL}$. Afterwards, Lin et al. $[65,66]$ used the FITC-anti-FITC system as the solid phase and the biotin-streptavidin system as the signal amplification system to develop a highly sensitive CLIA method for the determination of 17-estradiol (E2) and human thyroid stimulating hormone (hTSH), The LODs were $1.5 \mathrm{pg} / \mathrm{mL}$ and $0.01 \mathrm{mU} / \mathrm{L}$ respectively.

Magnetic microspheres have many advantages over conventional solid-phase microplates [67]. For example, microspheres can provide a relatively large surface area which allows for the utilization of a higher concentration 
of capture Abs enhancing the sensitivity of the assay; Ab-coated microspheres are freely suspended in the Agcontaining milieu and this results in more rapid reaction rates and reduces assay time by agitation of the mixture; Isolation of the microspheres containing $\mathrm{Ag}-\mathrm{Ab}$ complexes can be easily and rapidly performed under a simple magnetic field; Immunomagnetic microspheres are capable of capturing small amounts of analytes from a large, dilute sample volume. Thus, when the magnetic microspheres are collected, the total amount of analyte will be effectively concentrated. Table 4 shows the magnetic particles developed as solid phases for CLIA. Lin et al. [68-72] using the magnetic beads as second$\mathrm{Ab}$ separation agent and the first- $\mathrm{Ab}$ solid-surface developed the high sensitive CL enzyme IA method for the determination of estriol (E3), $\alpha$-fetoprotein (AFP), carcinoembryonic Ag (CEA), carbohydrate Ag 50 (CA50) in human serum with high sensitivity, specificity, rapidity, and reproducibility. Zhao et al. [73-75] developed a micro-plate magnetic CL enzyme IA through combining the microplate with magnetic beads as solid phase for the detection of human chorionic gonadotropin (HCG) in the serum and saliva matrix. For $17 \beta-$ estradiol (E2) in the environmental samples, they used the micro-plate magnetic separator designed by themselves [76] which can achieve high-throughput analysis without sample pre-treatment.

Magnetic bacteria have been isolated from fresh and marine sediments and are known to produce magnetic particles [77,78]. Much research has been carried out regarding the mechanism of production of these magnetic particles and their function as navigational compasses in vivo. The bacterial magnetic particles (BMPs) are small in size $(50-100 \mathrm{~nm})$ and disperse very well because they are covered with a stable lipid membrane. Enzymes and Abs have been immobilized on BMPs using both bifunctional reagents and glutaraldehyde and have been found to have higher activities than those immobilized onto artificial magnetic particles. Matsunaga et al. [79-81] developed a CL EIA using Ab-immobilized BMPs for the determination of mouse immunoglobulin $\mathrm{G}(\operatorname{IgG})$, E2, alkylphenol ethoxylates (APEs), bisphenol A (BPA) and linear alkylbenzene sulfonates (LASs) in environmental water. In order to obviate the need for immobilization of Ab to BMP by covalent chemical crosslinking, protein A-BMP complexes harvested from transconjugant AMB-1 were subsequently complexed with $\mathrm{Abs}$ by specific binding between the $\mathrm{Z}$ domain of protein $\mathrm{A}$ and the $\mathrm{Fc}$ component of IgG to form the $\mathrm{Ab}$ protein A-BMP complexes [85]. The complexes were quite monodisperse and that resulted in high signal and low noise in the IA. Lu et al. [86] introduced $\operatorname{poly}(\mathrm{N}$ isopropylacrylamide) (PNIP) and magnetic beads as bimolecular immobilizing carriers to separate different targets by taking advantage of thermal response employing homogeneous non-competitive ELISA formed by primary Abs immobilized onto the surface of magnetic beads and PNIP, Ag as IgG and IgA in the sample, and HRP-labeled second Abs. Moreover, highly sensitive CL detection of HRP was applied, and the LODs of IgG and IgA were as low as 2.0 and $1.5 \mathrm{ng} / \mathrm{mL}$, respectively.

\section{Combinations with other technologies}

\subsection{Flow injection}

CL analysis with the techniques of flow injection analysis (FIA) and IA combine all the advantages of the high sensitivity, high precision, high speed and high selectivity [53]. It has been widely applied to many fields including environmental monitoring, food safety, pharmaceutical analysis, and clinical diagnosis [87-89] due to its small sample-cost, reduced sample handling, acceptable reusability, good reproducibility, shorter time, and easy automation for high sample throughout. This technique can be performed in both homogeneous and heterogeneous systems. In heterogeneous flowinjection IA, the signal has to be modulated during formation of the Ag-Ab complex. Heterogeneous assays are more suitable for flow-injection IA (FIIA) because

Table 4. Development of magnetic particles as solid phases in chemiluminescence immunoassay (CLIA)

\begin{tabular}{|c|c|c|c|c|}
\hline Analytes & Solid phase & CL system & Limit of detection & Ref. \\
\hline E3 & Magnetic particles (MPs) & & $0.6 \mathrm{ng} / \mathrm{mL}$ & [68] \\
\hline AFP & MPs & ALP-AMPPD & $3.0 \mathrm{ng} / \mathrm{mL}$ & [70] \\
\hline CEA & MPs & ALP-AMPPD & $0.69 \mathrm{ng} / \mathrm{mL}$ & [71] \\
\hline CA50 & MPs & ALP-AMPPD & $1.0 \mathrm{U} / \mathrm{mL}$ & [72] \\
\hline $\mathrm{HCG}$ & MPs & ALP-AMPPD & $0.15 \mathrm{mIU} / \mathrm{mL}$ & [73] \\
\hline E2 & MPs & ALP-AMPPD & $5.4 \mathrm{pg} / \mathrm{mL}$ & [74] \\
\hline $\mathrm{mlg} G$ & BMPs & Lumi-phos 530-ALP & $1 \mathrm{fg} / \mathrm{mL}$ & [79] \\
\hline E2, APEs, BPA, LASs & BMPs & Lumi-phos 530-ALP & $20 \mathrm{ppt}, 6.6 \mathrm{ppb}, 2.3 \mathrm{ppt}, 35 \mathrm{ppt}$ & {$[80,81]$} \\
\hline $\begin{array}{l}\text { LAS, alkylphenol } \\
\text { polyethoxylates (APnEOs), } \\
\text { vitellogenin (Vg) }\end{array}$ & Magnetic beads & Luminol- $\mathrm{H}_{2} \mathrm{O}_{2}-\mathrm{HRP}-\mathrm{PIP}$ & $25 \mathrm{ppb}, 10 \mathrm{ppb}, 2 \mathrm{ng} / \mathrm{mL}$ & [82-84] \\
\hline Insulin & Protein A-BMP complexes & Lumi-phos 530-ALP & $2 \mu \mathrm{U} / \mathrm{mL}$ & [82] \\
\hline
\end{tabular}


the separation step can be carried out on-line in the FIIA system [90]. The separation step was performed through a packed bed reactor. Therefore, the selection of a suitable solid support for the reactor is one of the central decisions. The most commonly used supports include bead materials, such as silica, agarose, sepharose, polystyrene and membranes or magnetic particles. A heterogeneous FIIA system consists of a peristaltic multi-channel pump, an injection valve, the immunoreactor column, and the detector. Fig. 3 showed a flow-injection CL immunosensor for carbohydrate $\mathrm{Ag}$ 19-9 (CA19-9) based on the immobilization of CA19-9 on the cross-linked chitosan membrane [91]. After an off-line incubation of the analyte CA19-9 with HRPlabeled anti-CA19-9, the mixture was injected into the immunosensor, which led to the trapping of free HRPlabeled anti-CA19-9 by the immobilized $\mathrm{Ag}$ in the immunosensor. The trapped HRP-labeled Ab was detected by CL due to its catalytic activity following the reaction of luminol and $\mathrm{H}_{2} \mathrm{O}_{2}$. Under optimal

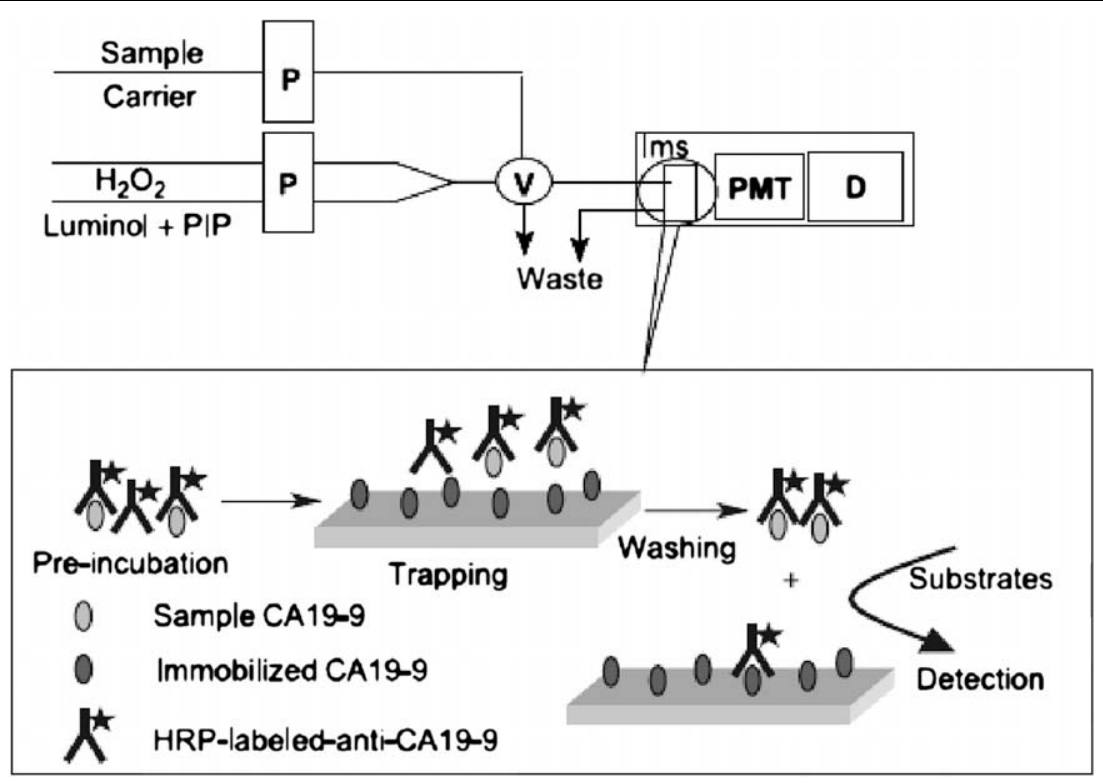

Figure 3. Chemiluminescent non-competitive flow-injection immunoassay system: P, Peristaltic pump; V, Eight-way valve; Ims, Immunosensor; PMT, Photo-multiplier; D, Detector [91].

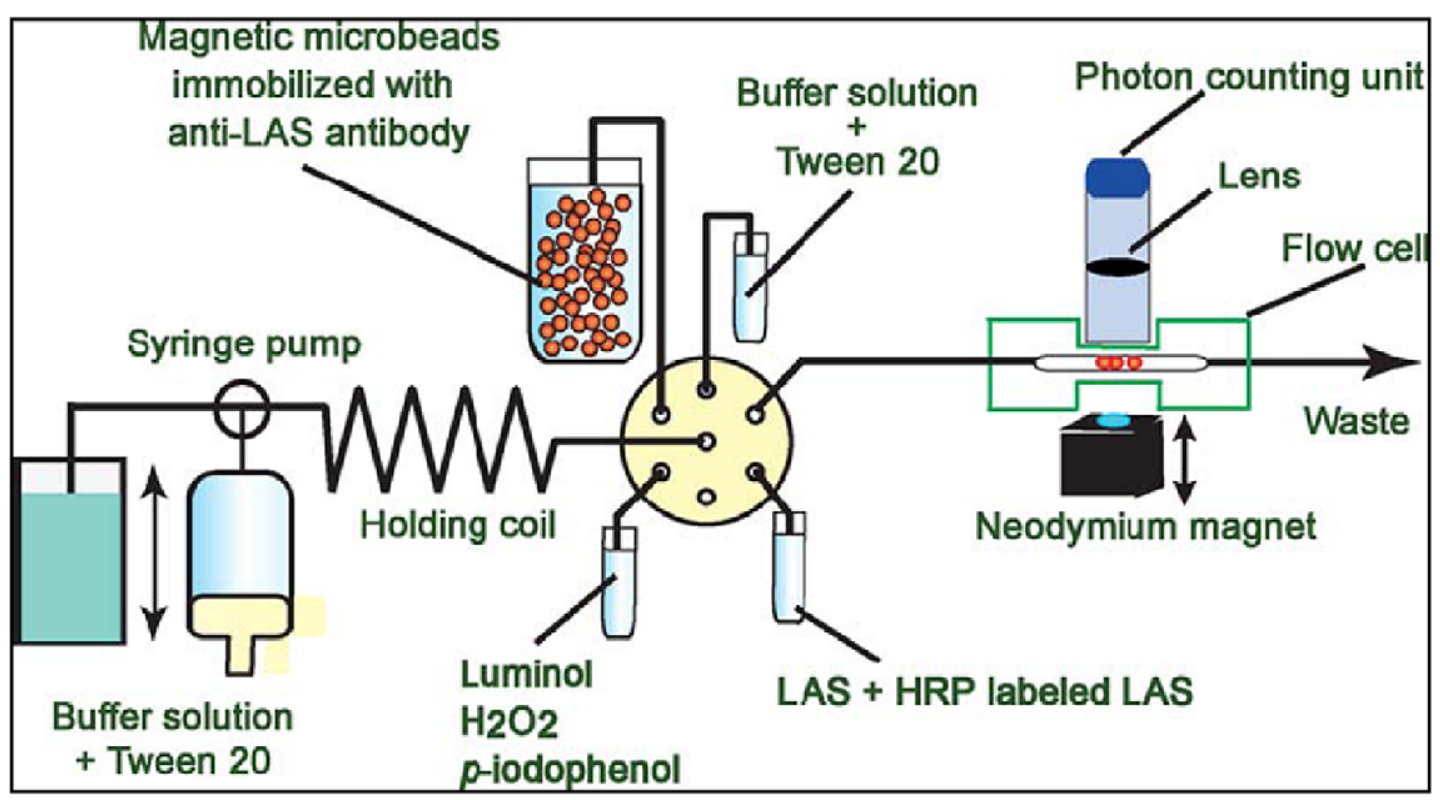

Figure 4. Sequential injection system using magnetic microbeads [97]. 
conditions, the decreased CL signal of the immunosensor was proportional to the CA19-9 concentration in the range $2.0-25 \mathrm{U} / \mathrm{mL}$ with an LOD of $1.0 \mathrm{U} / \mathrm{mL}$. Adopting the same scheme of flow-injection CLIA, the group developed the different immunoaffinity reactor prepared with epoxysilane modified glass microbeads [92], sepharose [93] and carboxylic resin beads [94] for the determination of clinical analytes.

The new variation of FIA, sequential injection analysis (SIA), introduced by Ruzicka and Marshall [95], also found application in CLIA [96]. Differing from FIA, in SIA, the different solutions are sequentially aspirated into the single reaction channel using a cam-driven sinusoidal flow piston pump in connection with a multiport-multiposition. Imato et al. [97,98] developed a rapid and sensitive IA based on SIA using magnetic microbeads for the determination of linear alkylbenzene sulfonates (LASs) and alkylphenol polyethoxylates (APnEOs) (as shown in Fig. 4). The introduction, trapping and release of the magnetic beads in the flow cell were controlled by means of a neodymium magnet and adjusting the flow of the carrier solution. The IA was based on an indirect competitive immunoreaction of an anti-LAS (or anti-APnEO) $\mathrm{mAb}$ on the magnetic beads and the LAS (or APnEO) sample and HRP-labeled LAS (or APnEO), and was based on the subsequent CL reaction of HRP with hydrogen peroxide and $p$-iodophenol, in a luminol solution. Under optimum conditions, the time required for analysis was less than $15 \mathrm{~min}$.

\subsection{Capillary electrophoresis}

Capillary electrophoresis IA (CEIA) combining the effective separation power of $\mathrm{CE}$ and the ligand specificity of IA has proved to be a powerful technique for the separation and analysis of biological compounds [99]. Compared to conventional IA, CEIA is characterized by high efficiency, less samples, short analysis time, and easy automation. It has been successfully applied to determine certain tumor markers, hormones and abuse drugs \{e.g., human growth hormone (hGH), insulin, morphine, cortisol and digoxin $[100,101]\}$.

Over the past decade, research in combining CE with CL detection has increased significantly due to its high sensitivity, easy operation, and inexpensive apparatus and reagents [102]. And some attention has been paid to its application in CEIA. Tsukagoshi et al. [103] demonstrated a CEIA experiment using mouse IgG and HRPlabeled anti-mouse IgG $\mathrm{Ab}$ in a newly designed batchtype CL detection cell for CE. Wang et al. [104] successfully detected bone morphogenic protein-2 (BMP-2) in rat vascular smooth muscle (VSM) cells with noncompetitive format by CEIA based on enhanced CL detection. HRP-Ab2-mAb-BMP-2 complex and free HRP were baseline separated and detected with LODs of $4.4 \times 10^{-12} \mathrm{~mol} / \mathrm{L} \quad(53 \mathrm{zmol})$ for HRP and $6.2 \times 10^{-12} \mathrm{~mol} / \mathrm{L}(75 \mathrm{zmol})$ for BMP-2. Ji et al. [105] developed a CEIA method with CL detection for the determination of CLB based on the competitive reaction between HRP-labeled CLB and free CLB with a limited amount of anti-CLB antiserum. Under optimal conditions, the tracer CLB-HRP and the IA complex were separated, and the linear range and the LOD $(S / N=3)$ for CLB were $5.0-40 \mathrm{nmol} / \mathrm{L}$ and $1.2 \mathrm{nmol} / \mathrm{L}$. CEIA based on CL was also successfully applied for the determination of the tumor Ag CA125 [106], hepatitis B surface $\mathrm{Ag}$ (HBsAg) and $\mathrm{Ab}$ (HBsAb) [107] in human serum.

\subsection{Chip capillary electrophoresis}

Miniaturized IA methods using on-chip capillary electrophoresis as a separation method on optical (LIF and CL) detection have been reported [108-110] with

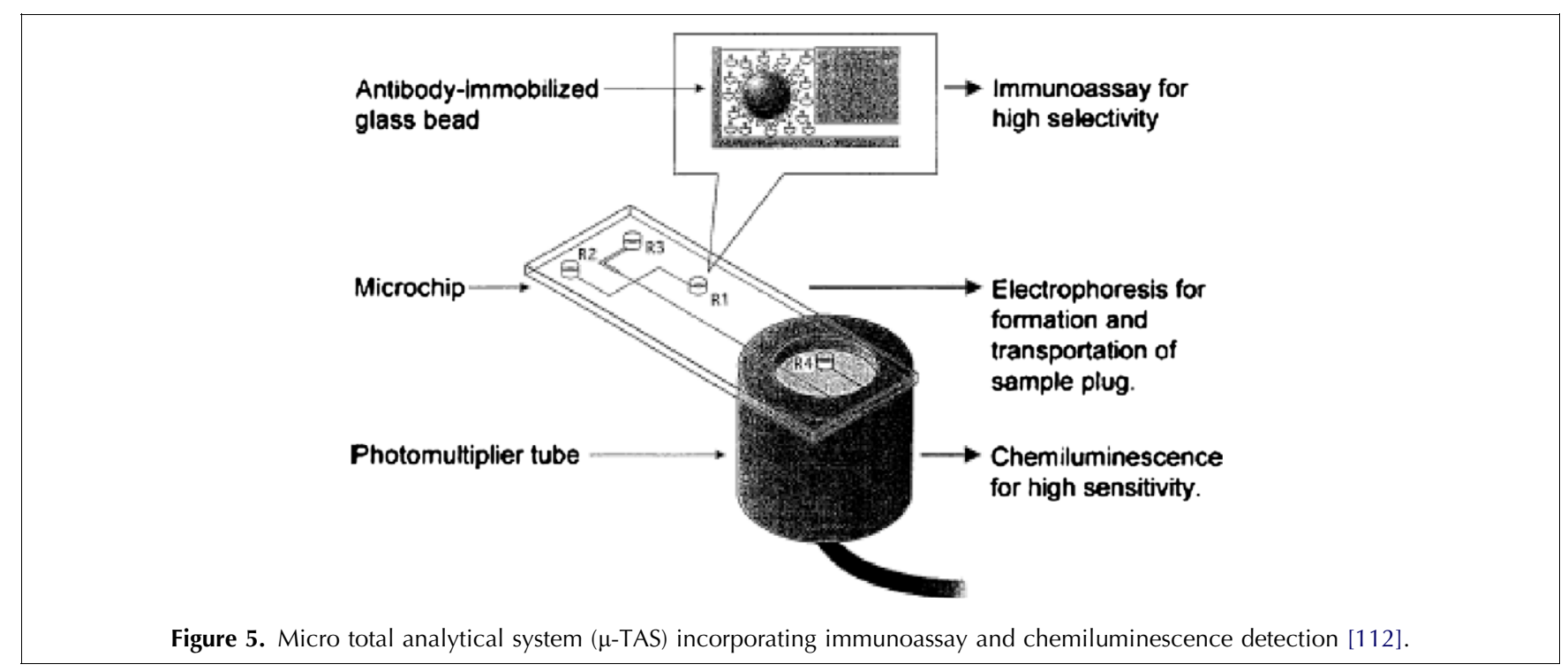


advantages of good reproducibility and shorter reaction times. However, fluorescent dye-labeled $\mathrm{Ab}$ is observed in capillary electrophoresis as a broad peak due to the charge heterogeneity of $\mathrm{Ab}$ itself [111], and this affects the LOD by decreasing the signal-to-noise ratio.

Tsukagoshi et al. [112] developed a micro total analysis system ( $\mu$-TAS) incorporating CL detection for the cancer marker. The analysis system performed the following three processes on a microchip: immune reaction for high selectivity, electrophoresis for formation and transportation of the sample plug, and CL detection for high sensitivity. The three processes were compactly integrated onto the microchip to give the $\mu$-TAS, as shown in Fig. 5. The microchip contained two microchannels that crossed at an intersection, while the ends of the microchannels accessed four reservoirs. As the first process, the immune reaction was performed using an Ab-immobilized glass bead. The glass bead was placed in one of the reservoirs along with $\mathrm{Ag}$ (analyte) and a known amount of ILITC-labeled Ag to set up a competitive immune reaction. For electrophoresis, as the second
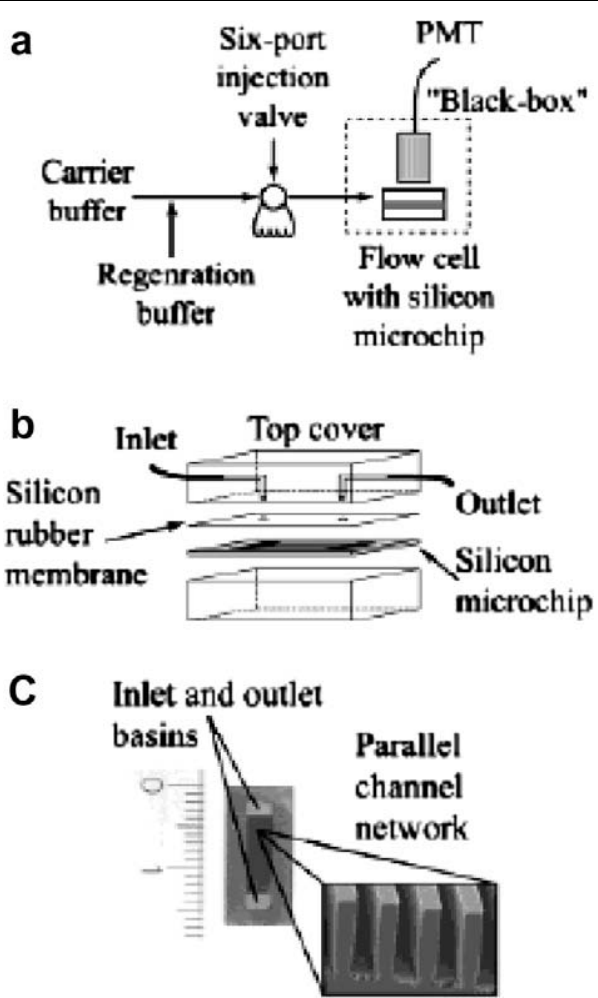

Figure 6. (a) Microfluidic enzyme immunoassay manifold. A syringe pump and a peristaltic pump were used for carrier buffer and regeneration buffer, respectively. Sample injection was made through a six-port injection valve. The chemiluminescence signal was measured with a photomultiplier tube placed above the flow cell containing the silicon microchip with immobilized antibodies. (b) Plexiglass microchip flow cell. (c) Microchip beside a ruler and a magnified picture of the parallel channel network [113]. process, the reactant after the immune reaction was fed electrophoretically into the intersection resulting in a sample plug. The sample plug was then moved into another reservoir containing hydrogen peroxide solution. At this point, CL detection was performed as the third process: the labeled $\mathrm{Ag}$ mixed with the hydrogen peroxide and the catalyst included in the migration buffer to produce CL. CL was detected by a photomultiplier tube located under the reservoir. The $\mu$-TAS described here was capable of determining, with high selectivity and sensitivity, human serum albumin or immunosuppressive acidic protein as a cancer marker in human serum.

Emneus et al. [113] used a silicon microchip as matrix to incorporate a microfluidic enzyme IAs using enhanced FI-CL detection of HRP label catalyzing the luminol/ $\mathrm{H}_{2} \mathrm{O}_{2} / p$-iodophenol (PIP) reaction based on Ab-coated silicon microchips. As shown in Fig. 6. polyclonal antiatrazine Abs were coupled to the silicon microchip surface and the assay principle was based on a direct competitive heterogeneous format in which the analyte and an enzyme-labeled atrazine (tracer) competed for immobilized $\mathrm{Ab}$ binding sites, following separation and detection of the bound tracer, generating the CL signal directly on the chip.

\subsection{Challenges in combining technologies}

The future of various IA technologies is generally driven by the needs of the biological, environmental, clinical or medical fields. Apparently, biological samples (e.g., saliva, plasma, human serum, spinal fluid and biopsy samples) contain important disease biomarkers or proteins present in a chaotic sample matrix, wherein both the minute concentration and the dynamic range for each Ag must be considered. The current nascent technology for sample detection of clinically or environmental important Ags is very encouraging with LODs approaching an amol level and simultaneous multiple analyte determination. Also there have been significant trends towards microminiaturization, automation, costeffective and multiplex analysis. So, microfluidic IA devices possess remarkable features such as high surface-to-volume ratio and $\mathrm{nL}$ volume of microchannel. However, chip-CE-CLIA technology has been restricted to CLIA inside a microfluidic device where Ags or Abs are delivered inside a microchannel by electrokinetic- or pressure-driven flow. Current advancement is geared towards passive actuation of pumps, valves and mixers. This is not surprising since it makes fluid control easy by eliminating other macroscopic moving parts, ultimately realizing a cost-effective microchip. Now, fabrication of microfluidic IA chips is moving rapidly towards a simple, portable point-of-care diagnostic devices as shown by various trends like the use of polymer material, passive fluid control and on-chip detection. Moreover, the combination of magnetic microparticles and NPs prove 
to be a formidable pair that allows not only signal enhancement but also ease of fluid manipulation in the presence of a magnetic field especially in microfluid IA.

\section{Future outlook}

Significant trends in analytical chemistry have been towards microminiaturization, the improvement of sensitivity and multiplex analysis. Miniaturized CL reactors, high-density arrays of reaction vessels and microchipbased analyzers, which require very small amounts of samples and reagents, have been developed [114]. The high detectability and rapidity of CL techniques, along with the availability of microarray-based analytical devices, allows the development of high throughput screening assays, in which simultaneous, multi-analyte detection is performed on multi samples.

Improvements in analytical sensitivity will likely lead to the discovery of new analytes for environmental pollution or disease detection. Technical enhancement holds the promise of detecting extremely low concentrations in serum using NPs as labels and CL detection [39-47]. The binding of oligonucleotides to NPs has particular promise. Use of these very small particles enables a high sensitivity. Zhang et al. [115], using the Au and CuS as labels and CL detection for the DNA detection, found that sensitivity has improved 6 times compared with other methods. Use of this immuno NP assay has enabled the detection of 18-20 $\alpha$-fetoprotein molecules in $10 \mu \mathrm{L}$, some 6 -log higher sensitivity than conventional IA [116].

Multiplex analysis allows for the simultaneous measurement of many analytes that are commonly grouped. Multivariate analysis on microchip, where different haptens or Abs were immobilized in distinct areas on a glass surface, has been used to perform multi-analyte detection based on conventional CL IA procedures. The analysis of the spatial pattern of the light output, measured via an imaging charge-coupled device (CCD) device, allowed the detection of the different analytes [117]. Recent work includes the parallel affinity sensor assay (PASA) which used automated chip-multi-analyte IA with an indirect competitive ELISA format and a CL reaction monitored by a charge-coupled device (CCD) camera for the simultaneous detection of antibiotics in milk [118] and allergy diagnosis [119], and the development of miniaturized CE separative system with CL detection using miniaturized microchip fabrication technology [120].

\section{Acknowledgements}

We acknowledge financial support from the CAS Major Scientific Research and Equipment Development Projects
(YZ-0632), the National Key Technology R\&D Program (2006BAF07B03-1-1) and the CAS Graduate Innovation Foundation (No.YXLW-3).

\section{References}

[1] S.A. Berson, R.S. Yalow, Nature (London) 184 (1959) 1648.

[2] I. Surugiu, J. Svitel, L. Ye, K. Haupt, B. Danielsson, Anal. Chem. 73 (2001) 4388.

[3] Z.P. Li, Y.C. Wang, C.H. Liu, Y.K. Li, Anal. Chim. Acta 551 (2005) 85.

[4] C.A. Marquette, P. Hezard, A. Degiuli, L.J. Blum, Sens. Actuators, Part B 113 (2006) 664.

[5] M.Z. Zheng, J.L. Richard, J. Binder, Mycopathologia 161 (2006) 261.

[6] L.R. Luo, Z.J. Zhang, L.Y. Hou, J.L. Wang, W. Tian, Talanta 72 (2007) 1293.

[7] D. Knopp, Anal. Bioanal. Chem. 385 (2006) 425.

[8] A. Gao, Q. Chen, Y. Cheng, J. Lei, L. Zeng, Anal. Chim. Acta 592 (2007) 58.

[9] M.P. Bruce, V. Boyd, C. Duch, J.R. White, J. Immunol. Methods 264 (2002) 59.

[10] K.Y.F. Yau, H. Lee, J.C. Hall, Biotechnol. Adv. 21 (2003) 599.

[11] J. Brichta, M. Hnilova, T. Viskovic, Vet. Med. Czech 50 (2005) 231.

[12] D. Rau, K. Kramer, B. Hock, Anal. Bioanal. Chem. 372 (2002) 261.

[13] M.J. Alcocer, C. Doyen, H.A. Lee, M.R. Morgan, J. Agric. Food Chem. 48 (2000) 335.

[14] K.Y.F. Yau, N.L. Tout, H. Lee, J.T. Trevors, J.C. Hall, J. Agric. Food Chem. 46 (1998) 4457.

[15] L. Dexlin, J. Ingvarsson, B. Frendéus, C.A.K. Borrebaeck, C. Wingren, J. Proteome Res. 7 (2008) 319.

[16] N. Lee, C.K. Holtzapple, L.H. Stanker, J. Agric. Food Chem. 46 (1998) 3381

[17] V. Va1isa1nen, M.T. Peltola, H. Lilja, M. Nurmi, K. Pettersson, Anal. Chem. 78 (2006) 7809.

[18] K. Pan, H. Wang, H.-B. Zhang, H.-W. Liu, H.-T. Lei, L. Huang, Y.-M. Sun, J. Agric. Food Chem. 54 (2006) 6654.

[19] B. Lauer, I. Ottleben, H.R. Jacobsen, T. Reinard, J. Agric. Food Chem. 53 (2005) 899.

[20] T. Li, Q. Zhang, Y. Liu, D. Chen, B. Hu, D.A. Blake, F. Liu, J. Agric. Food Chem. 54 (2006) 9085.

[21] I. Shaw, A. O'Reilly, M. Charleton, M. Kane, Anal. Chem. 80 (2008) 3205.

[22] F. Olea-Popelka, M.D. McLean, J. Horsman, K. Almquist, J.E. Brandle, J.C. Hall, J. Agric. Food Chem. 53 (2005) 6683.

[23] K. Haupt, K. Mosbach, Trends Biotechnol. 16 (1998) 468.

[24] G. Vlatakis, L.I. Andersson, R. Muller, K. Mosbach, Nature (London) 361 (1993) 645.

[25] M. Siemann, L.I. Andersson, K. Mosbach, J. Agric. Food Chem. 44 (1996) 141.

[26] S.A. Piletsky, E.V. Piletska, B. Chen, K. Karim, D. Weston, G. Barrett, P. Lowe, A.P.F. Turner, Anal. Chem. 72 (2000) 4381.

[27] F. Vandevelde, T. Leichle, C. Ayela, C. Bergaud, L. Nicu, K. Haupt, Langmuir 23 (2007) 6490.

[28] I. Surugiu, B. Danielsson, L. Ye, K. Mosbach, K. Haupt, Anal. Chem. 73 (2001) 487.

[29] K. Haupt, A.G. Mayes, K. Mosbach, Anal. Chem. 70 (1998) 3936.

[30] H.-H. Yang, S.-Q. Zhang, F. Tan, Z.-X. Zhuang, X.-R. Wang, J. Am. Chem. Soc. 127 (2005) 1378.

[31] H.R. Schroeder, P.O. Vogelhut, R.J. Carrico, R.C. Boguslaski, R.T. Buckler, Anal. Chem. 48 (1976) 1933.

[32] W.R. Seitz, Clin. Biochem. 17 (1984) 120. 
[33] H.-S. Zhuang, J.-L. Huang, G.-N. Chen, Anal. Chim. Acta 512 (2004) 347.

[34] A. Scorilas, K. Agiamarnioti, K. Papadopoulos, Clin. Chim. Acta 357 (2005) 159.

[35] H.L. Qi, C.X. Zhang, Anal. Chim. Acta 501 (2004) 31.

[36] L.N. Lewis, Chem. Rev. 93 (1993) 2693.

[37] J.F. Smyth, Science (Washington, DC) 258 (1992) 414.

[38] H. Weller, Angew. Chem., Int. Ed. Engl. 35 (1996) 1079.

[39] Z.-P. Li, Y.-C. Wang, C.-H. Liu, Y.-K. Li, Anal. Chim. Acta 551 (2005) 85.

[40] C.-H. Liu, Z.-P. Li, B.-A. Du, X.-R. Duan, Y.-C. Wang, Anal. Chem. 78 (2006) 3738.

[41] D. Hu, H. Han, R. Zhou, F. Dong, W. Bei, F. Jia, H. Chen, Analyst (Cambridge, UK) 133 (2008) 768.

[42] S. Gupta, S. Huda, P.K. Kilpatrick, O.D. Velev, Anal. Chem. 79 (2007) 3810

[43] A. Fan, C. Lau, J. Lu, Anal. Chem. 77 (2005) 3238.

[44] Z.P. Li, C.H. Liu, Y.S. Fan, Y.C. Wang, X.R. Duan, Anal. Biochem. 359 (2006) 247.

[45] Z. Wang, J. Hu, Y. Jin, X. Yao, J. Li, Clin. Chem. 52 (2006) 1958.

[46] G. Jie, H. Huang, X. Sun, J.-J. Zhu, Biosens. Bioelectron. 23 (2008) 1896.

[47] Z.-P. Li, C.H. Liu, Y.S. Fan, Y.C. Wang, X.R. Duan, Anal. Bioanal. Chem. 387 (2007) 613.

[48] R. Gill, R. Freeman, J.P. Xu, I. Willner, S. Winograd, I. Shweky, U. Banin, J. Am. Chem. Soc. 128 (2006) 15376.

[49] Z. Zhelev, R. Bakalova, H. Ohba, R. Jose, Y. Imai, Y. Baba, Anal. Chem. 78 (2006) 321.

[50] H.-B. Wei, J.-M. Lin, D.-N. Wu, L.-X. Zhao, Z.-J. Li, X.-T. Ying, Chin. J. Anal. Chem. 35 (2007) 320.

[51] G. Shi, B.-J. Tang, X. Wang, L. Zhao, J.-M. Lin, Chin. J. Anal. Chem. 35 (2007) 1541.

[52] Y. Dotsikas, Y.L. Loukas, I. Siafaka, Anal. Chim. Acta 459 (2002) 177.

[53] J.-X. Luo, X.-C. Yang, Anal. Chim. Acta 485 (2003) 57.

[54] Y. Dotsikas, Y.L. Loukas, Anal. Chim. Acta 509 (2004) 103.

[55] Y. Dotsikas, Y.L. Loukas, Talanta 71 (2007) 906.

[56] Y.-D. Wu, C.-L. Wong, K.W.K. Chan, G.-Z. Ji, X.-K. Jiang, J. Org. Chem. 61 (1996) 746.

[57] J. Lind, X. Shen, T.E. Eriksen, G. Merenyi, J. Am. Chem. Soc. 112 (1990) 479.

[58] I.Y. Sakharov, Biochemistry (Moscow) 66 (2001) 515.

[59] I.S. Alpeeva, I.Y. Sakharov, J. Agric. Food Chem. 53 (2005) 5784.

[60] I.Y. Sakharov, I.S. Alpeeva, E.E. Efremov, J. Agric. Food Chem. 54 (2006) 1584.

[61] S.-Q. Ren, X. Wang, B.-J. Tang, G.-M. Hu, Z.-J. Li, G.-N. Chen, J.M. Lin, Chin. J. Anal. Chem. 36 (2008) 729.

[62] Z. Lin, X. Wang, S.-Q. Ren, G.-N. Chen, Z.-J. Li, J.-M. Lin, Chin. J. Anal. Chem. 36 (2008) 609.

[63] X. Wang, H. Chen, J.-M. Lin, X.-T. Ying, Int. J. Biol. Sci. 3 (2007) 274.

[64] L. Zhao, J.-M. Lin, Z. Li, Anal. Chim. Acta 541 (2005) 199.

[65] L. Zhao, J.-M. Lin, Z. Li, X. Ying, Anal. Chim. Acta 558 (2006) 290.

[66] Z. Lin, X. Wang, Z. Li, S.-Q. Ren, G.-N. Chen, X. Ying, J.-M. Lin, Talanta 75 (2008) 965.

[67] H. Yu, J.W. Raymonda, T.M. McMahon, A.A. Campagnari, Biosens. Bioelectron. 14 (2000) 829.

[68] D.N. Wu, X. Wang, J.-M. Lin, Z.J. Li, X.T. Ying, Acta Chim. Sinica 65 (2007) 2755.

[69] D.N. Wu, J.-M. Lin, Z.J. Li, X. Wang, X.T. Ying, Chin. J. Anal. Chem. 35 (2007) 1241.

[70] X. Wang, Q.-Y. Zhang, Z.-J. Li, X.-T. Ying, J.-M. Lin, Clin. Chim. Acta 393 (2008) 90.

[71] W. Dungchai, W. Siangproh, J.-M. Lin, O. Chailapakul, S. Lin, X. Ying, Anal. Bioanal. Chem. 387 (2007) 1965.
[72] X. Wang, J.-M. Lin, X. Ying, Anal. Chim. Acta 598 (2007) 261.

[73] L.X. Zhao, J.-M. Lin, F. Qu, Acta Chim. Sinica 62 (2004) 71.

[74] L. Zhao, J.-M. Lin, J. Biotechnol. 118 (2005) 177.

[75] T.-B. Xin, S.-X. Liang, Z.-J. Li, X.-T. Ying, J.-M. Lin, Anal. Chim. Acta 627 (2008) 277.

[76] J.-M. Lin, L. X. Zhao, F. Qu, A microplate magnetic separator for magnetic immunoassay, Chinese Invention Patent, ZL 03138349.1.2005.

[77] R.P. Blakemore, Science (Washington, DC) 190 (1975) 377.

[78] T. Sakaguchi, J.G. Burgess, T. Matsunaga, Nature (London) 365 (1993) 47.

[79] T. Matsunaga, M. Kawasaki, X. Yu, N. Tsujimura, N. Nakamura, Anal. Chem. 68 (1996) 3551.

[80] T. Tanaka, H. Takeda, F. Ueki, K. Obata, H. Tajima, H. Takeyama, Y. Goda, S. Fujimoto, T. Matsunaga, J. Biotechnol. 108 (2004) 153.

[81] T. Matsunaga, F. Ueki, K. Obata, H. Tajima, T. Tanaka, H. Takeyama, Y. Goda, S. Fujimoto, Anal. Chim. Acta 475 (2003) 75.

[82] R.Q. Zhang, K. Hirakawa, D. Seto, N. Soh, K. Nakano, T. Masadome, K. Nagata, K. Sakamoto, T. Imato, Talanta 68 (2005) 231

[83] R.Q. Zhang, H. Nakajima, N. Soh, K. Nakano, T. Masadome, K. Nagata, K. Sakamoto, T. Imato, Anal. Chim. Acta 600 (2007) 105.

[84] N. Soh, H. Nishiyama, Y. Asano, T. Imato, T. Masadome, Y. Kurokawa, Talanta 64 (2004) 1160.

[85] T. Tanaka, T. Matsunaga, Anal. Chem. 72 (2000) 3518.

[86] Y. Zhou, Y. Zhang, C. Lau, J. Lu, Anal. Chem. 78 (2006) 5920.

[87] Z.F. Fu, F. Yan, H. Liu, Z.J. Yang, H.X. Ju, Biosens. Bioelectron. 23 (2008) 1063.

[88] Z.F. Fu, Z.J. Yang, J.H. Tang, H. Liu, F. Yan, H.X. Ju, Anal. Chem. 79 (2007) 7376.

[89] J. Wu, F. Yan, J.H. Tang, C. Zhai, H.X. Ju, Clin. Chem. 53 (2007) 1495.

[90] G. Gubitz, M.G. Schmid, H. Silviaeh, H.Y. Aboul-Enein, Crit. Rev. Anal. Chem. 31 (2001) 167.

[91] J. Lin, F. Yan, X. Hu, H. Ju, J. Immunol. Methods 291 (2004) 165.

[92] Z. Fu, C. Hao, X. Fei, H. Ju, J. Immunol. Methods 312 (2006) 61.

[93] J. Lin, F. Yan, H. Ju, Clin. Chim. Acta 341 (2004) 109.

[94] Z. Yang, Z. Fu, F. Yan, H. Liu, H. Ju, Biosens. Bioelectron. 24 (2008) 35 .

[95] J. Ruzicka, G.D. Marshall, Anal. Chim. Acta 237 (1990) 329.

[96] C.H. Pollema, J. Ruzicka, G.D. Christian, A. Lernmark, Anal. Chem. 64 (1992) 1356

[97] R. Zhang, K. Hirakawa, D. Seto, N. Soh, K. Nakano, T. Masadome, K. Nagata, K. Sakamoto, T. Imato, Talanta 68 (2005) 231

[98] R. Zhang, H. Nakajima, N. Soh, K. Nakano, T. Masadome, K. Nagata, K. Sakamotod, T. Imato, Anal. Chim. Acta 600 (2007) 105.

[99] N.M. Schultz, R.T. Kennedy, Anal. Chem. 65 (1993) 3161.

[100] W.S.B. Yeung, G.A. Luo, Q.G. Wang, J.P. Ou, J. Chromatogr., B 797 (2003) 217.

[101] S.M. Lin, S.M. Hsu, Anal. Biochem. 341 (2005) 1.

[102] R.G. Su, J.M. Lin, K. Uchiyama, M. Yamada, Talanta 64 (2004) 1024.

[103] K. Tsukagoshi, T. Nakamura, R. Nakajima, Anal. Chem. 74 (2002) 4109.

[104] J. Wang, W. Huang, Y. Liu, J. Cheng, J. Yang, Anal. Chem. 76 (2004) 5393.

[105] X. Ji, Z. He, X. Ai, H. Yang, C. Xu, Talanta 70 (2006) 353.

[106] J.N. Wang, J.C. Ren, Electrophoresis 26 (2005) 2402.

[107] Y. Zhang, Z. Zhang, F. Yang, J. Chromatogr., B 857 (2007) 100

[108] K.A. Feller, Biosens. Bioelectron. 22 (2007) 1368. 
[109] M.W. Toepke, S.H. Brewer, D.M. Vu, K.D. Rector, J.E. Morgan, R.B. Gennis, P.J.A. Kenis, R.B. Dyer, Anal. Chem. 79 (2007) 122.

[110] J.F. Dishinger, R.T. Kennedy, Anal. Chem. 79 (2007) 947.

[111] Y. Mimura, K. Nakamura, T. Tanaka, M. Fujimoto, Electrophoresis 19 (1998) 767.

[112] K. Tsukagoshi, N. Jinno, R. Nakajima, Anal. Chem. 77 (2005) 1684.

[113] J. Yakovleva, R. Davidsson, A. Lobanova, M. Bengtsson, S. Eremin, T. Laurell, J. Emneus, Anal. Chem. 74 (2002) 2994.

[114] A. Roda, P. Pasini, M. Guardigli, M. Baraldini, M. Musiani, M. Mirasoli, Fresenius' J. Anal. Chem. 366 (2000) 752.
[115] S. Zhang, H. Zhong, C. Ding, Anal. Chem. 80 (2008) 9124.

[116] J.M. Nam, C.S. Thaxton, C.A. Mirkin, Science (Washington, DC) 301 (2003) 1884.

[117] A.J. Schuetz, M. Winklmair, M.G. Weller, Bioluminescence and Chemiluminescence: Perspective for the 21st Century, Wiley, Chichester, West Sussex, UK, 1999 p. 67.

[118] B.G. Knecht, A. Strasser, R. Dietrich, E. Martlbauer, R. Niessner, M.G. Weller, Anal. Chem. 76 (2004) 646.

[119] B.I. Fall, B. Eberlein-Konig, H. Behrendt, R. Niessner, J. Ring, M.G. Weller, Anal. Chem. 75 (2003) 556.

[120] E. Yacoub-George, W. Hell, L. Meixner, F. Wenninger, K. Bock, P. Lindner, H. Wolf, T. Kloth, K.A. Feller, Biosens. Bioelectron. 22 (2007) 1368. 